\title{
Can Antibiotic Prophylaxis Prior to Surgical Removal of Teeth reduce the Incidence of Post-operative Infections?
}

\author{
Avan Mohammed* and Karishma Dusara \\ The Royal London Hospital, Barts Health NHS Trust, London, UK
}

Received: November 20, 2013, Accepted: January 02, 2014, Published: January 07, 2014

*Corresponding author: Avan Mohammed, Department of Oral and Maxillofacial Surgery, The Royal London Hospital, Barts Health NHS Trust, London, UK, Email: avan.mohammed@nhs.net

\begin{abstract}
Introduction: Despite the ongoing debate with regards to the use of antibiotic prophylaxis during surgical extractions and whether they should be administered at all, patients attending for surgical removal of teeth may receive antibiotics before and/or after surgery. This review examined the evidence for the use of pre-operative antibiotic prophylaxis for patients undergoing surgical tooth removal.

Method: A literature search was performed on PubMed and a thorough literature appraisal was undertaken of all relevant articles obtained.

Results: Out of all the eleven articles retrieved in the search only two fit the inclusion criteria. Both articles concluded that there is limited evidence for the use of pre-operative antibiotics prior to the surgical removal of teeth.

Conclusion: Although the clinical evidence is limited, preoperative antibiotic prophylaxis may help to reduce the incidence of post-operative infections in susceptible patients who are undergoing surgical removal of teeth. However, further research is necessary in this field.
\end{abstract}

Keywords: Pre-surgical, Antibiotic Prophylaxis, Surgical Exodontias, Dry Socket, Post-Operative Infection

\section{Introduction}

Dento-alveolar surgery and increased surgical trauma to tissues can result in a number of post-operative complications including the development of infections in the surgical site [1]. An oral surgeon who gives prophylaxis therapy may wish to do so bacterial load in the blood and therefore reduce the risk of postoperative complications such as pain, swelling as well as postoperative infections including a dry socket (alveolar osteitis). However there are no local or national guidelines that exist which support the use of pre-operative antibiotic prophylaxis. With the existence of conflicting evidence, the use of pre-operative and/or post-operative antibiotics remains controversial.

Local post-operative infectionsanddry sockets (alveolar osteitis) can be caused by a number of risk factors. These include immunocompromisedpatients, oral contraceptives, smokers, traumatic extractions and the extraction of teeth with an existing infection [1].
Antibiotics are indicated as an adjunct alongside local measures for the management of post-operative spreading infections and where there is evidence of cellulitis, increased temperature and trismus [1]

The current literature does not support the routine use of antibiotic prophylaxis in patients undergoing surgical removal of teeth including wisdom teeth. A recent Cochrane review [1] suggests that there is moderate evidence to support prophylaxis use to reduce the risk of dry socket (alveolar osteitis) and postoperative infection of surgical sites. This evidence does not however outweigh the risks associated with the use of antibiotics such as anaphylactic reactions and the development of resistant bacteria, and therefore antibiotics must not be prescribed routinely. The Cochrane review only refers to post-operative antibiotic therapy and there is no mention to the use of preoperative antibiotic prophylaxis.

Another recent review by Cochrane looked at the treatment that can be used to prevent and treat dry socket [2]. However the review which included 21 clinical trials excluded studies which looked at the use of antibiotic prophylaxis in the management of dry socket.

Despite the conflicts that exist around this topic, some oral surgeons still use antibiotic prophylaxis routinely as a method to reduce the incidence of post-operative infections. Some surgeons ask their anaesthetists to provide intravenous antibiotic prophylaxis for patients undergoing treatment under general anaesthesia.

The aim of this systematic literature search was to determine the scientific evidence for the benefit, if any, for the use of antibiotic prophylaxis prior to surgical removal of teeth to prevent post-operative infections.

\section{Method}

\section{Clinical question}

A PICO format (population/patient/problem, intervention, comparison/control, outcome) was used to structure the following question: 
For patient undergoing surgical removal of teeth (population) does pre-surgical antibiotic prophylaxis (intervention) compared to no antibiotic prophylaxis (comparison) reduce the incidence of post operative infections in the surgical site (outcome)?

\section{Search strategy}

A search strategy was created on PubMed using the designed PICO question (Table 1). The search included the following keywords and their respective MeSH terms which included pre - surgical antibiotic prophylaxis, pre - operative, antibiotic prophylaxis, surgical exodontias, surgical tooth removal, surgical tooth extraction, dry socket, alveolar osteitis and post-operative infection.

The search was further restricted to randomized controlled trials and a total of 11 articles were retrieved. These 11 articles were screened using the exclusion and inclusion criteria below.

\section{Eligibility and study selection}

Studies were limited to systematic reviews and randomized controlled trials with no language restriction. The inclusion criteria included: surgical removal of teeth, pre - operative antibiotic prophylaxis, post-operative infection and dry socket. Studies that included pre - surgical antibiotic prophylaxis with continued post - surgical prophylaxis were excluded. There were no restrictions placed on patient selection, type of antibiotic used and the nature of the surgical procedure used (local anaesthetic, sedation or general anaesthetic).

Out of the 11 articles retrieved, one Nigerian study could not be found even though the authors were contacted and therefore it had to be excluded from the appraisal. Another study was on antibiotic prophylaxis for infective endocarditis and therefore this was excluded. A further 7 studies were excluded as they used pre-operative antibiotics with continued post-operative antibiotic prophylaxis. These studies did not address the question of this search and were therefore removed. Therefore a total of 2 articles out of the 11 retrieved were eligible for critical appraisal (Table 2).

\section{Results}

One randomized controlled trial by Bezerra et al. [3] conducted on fit and healthy patients with ASA (American Society of Anaesthesiologists) classification I or II, showed no significant difference between the intervention and the control group. The study was carried out in Brazil on 34 subjects and used oral antibiotic prophylaxis; two amoxicillin tablets were given to patients one hour pre-operatively. The placebo group received matching placebo capsules. The procedures were carried out by the same oral surgeon under local anaesthetic in an outpatient clinic.

All patients had at least one indication for the removal of all four third molar teeth. Patients underwent 4 surgical extractions on two clinical sessions using a split mouth design. All patients were re-evaluated pre-operatively on the 3rd, 7th and 14th day for clinical evidence of infection, increased body temperature and limited mouth opening. Approximately 50\% presented with
Table 1: Searched Strategy.

\begin{tabular}{|c|c|c|}
\hline $\begin{array}{l}\text { Search } \\
\text { number }\end{array}$ & Search term & $\begin{array}{l}\text { Retrieved } \\
\text { articles }\end{array}$ \\
\hline$\# 1$ & Surgical tooth extraction & 17048 \\
\hline \#2 & Surgical tooth removal & 17965 \\
\hline \#3 & Surgical exodontia & 17069 \\
\hline$\# 4$ & \#1 OR \#2 OR \#3 & 17986 \\
\hline \#5 & Pre operative antibiotic & 517 \\
\hline \#6 & Pre surgical antibiotic prophylaxis & 400 \\
\hline \#7 & Pre surgical antibiotic & 1605 \\
\hline \#8 & Pre surg* antibiotic & 35 \\
\hline$\# 9$ & \#8 OR \#7 OR \#6 OR \#5 & 1830 \\
\hline$\# 10$ & Post operative infection & 15129 \\
\hline \#11 & Dry socket & 743 \\
\hline \#12 & Alveolar osteitis & 851 \\
\hline \#13 & \#10 OR \#11 OR \#12 & 15957 \\
\hline$\# 14$ & \#4 AND \#9 AND \#13 & 5 \\
\hline \#15 & Antibiotic prophylaxis & 14394 \\
\hline \#16 & \#4 AND \#9 AND \#15 & 29 \\
\hline \#17 & $\begin{array}{l}\text { \#4 AND \#13 AND \#15 } \\
\text { Filters: Randomized Controlled Trial }\end{array}$ & 11 \\
\hline \#18 & $\begin{array}{l}\text { Antibiotic prophyla* } \\
\text { Filters: Randomized Controlled Trial }\end{array}$ & 1331 \\
\hline \#19 & $\begin{array}{l}\text { \#15 OR \#18 } \\
\text { Filters: Randomized Controlled Trial }\end{array}$ & 1609 \\
\hline \#20 & $\begin{array}{l}\text { \#19 AND \#4 AND \#13 } \\
\text { Filters: Randomized Controlled Trial }\end{array}$ & 11 \\
\hline \#21 & $\begin{array}{l}\text { Surg* tooth extraction } \\
\text { Filters: Randomized Controlled Trial }\end{array}$ & 830 \\
\hline \#22 & $\begin{array}{l}\text { Surg* tooth removal } \\
\text { Filters: Randomized Controlled Trial }\end{array}$ & 905 \\
\hline \#23 & $\begin{array}{l}\text { Surg* exodontia } \\
\text { Filters: Randomized Controlled Trial }\end{array}$ & 830 \\
\hline \#24 & $\begin{array}{l}\text { \#4 OR \#21 OR \#22 OR \#23 Filters: } \\
\text { Randomized Controlled Trial }\end{array}$ & 1108 \\
\hline \#25 & $\begin{array}{l}\text { \#24 AND \#13 AND \#19 } \\
\text { Filters: Randomized Controlled Trial }\end{array}$ & 11 \\
\hline
\end{tabular}

post-operative infection events on the 3rd day described by the authors as swellings, traumatic ulcers, dry socket and surgical wound infections. There was no significant difference between the 2 groups.

An increased mouth opening in the intervention group compared to the control only group on day $3(\mathrm{P}=0.29)$ was observed. There were two cases of dry socket; onein the intervention group presented on day 3 and one in the control group presented on day 7. Results also showed three cases of purulent discharge observed in the control group only. Overall, the results of the study did not show a statistically significant difference between the two groups.

Another randomized controlled trial was conducted by Halpern et al. [4] on 118 subjects in Massachusetts General Hospital between June 1, 2002 and July 1, 2005. This was a single centre and single surgeon study. All the subjects included in the study had at least one third molar removed either under intravenous sedation or general anaesthetic. The study excluded 
Table 2: Summary of relevant papers.

\begin{tabular}{|c|c|c|c|}
\hline Paper & Study Detail & Results/Conclusion & Weaknesses \\
\hline $\begin{array}{l}\text { Bezerra TP, et al (2011) } \\
\text { Prophylaxis versus placebo treatment } \\
\text { for infective and inflammatory } \\
\text { complications of surgical third molar } \\
\text { removal. A split-mouth, double } \\
\text { blind, controlled clinical trial with } \\
\text { Amoxicillin 500mg }\end{array}$ & $\begin{array}{l}\text { Design: Randomised, double blind } \\
\text { with split mouth design } \\
\text { Subject: } 34 \text { patients ages } 18-35 \\
\text { years with indication for the removal } \\
\text { of all four third molars } \\
\text { Intervention: } \\
\text { Two outpatient clinical sessions; } \\
\text { upper and lower impacted third } \\
\text { molars of the same side surgically } \\
\text { removed in each session. Patients } \\
\text { treated under Local Anaesthetic. } \\
\text { Two } 500 \text { mg Amoxicillin capsules } \\
\text { administered } 1 \text { hour pre operatively } \\
\text { Control: Placebo matching capsules } \\
\text { Outcome: Post operative data } \\
\text { collected on the } 3,7 \text { and } 14: \\
\text { 1. body temperature }>37.5^{\circ} \mathrm{C} \\
\text { 2. mouth opening } \\
\text { 3. clinical evidence of purulent } \\
\text { secretions/dry socket/oedema }\end{array}$ & $\begin{array}{l}\text { Total: } \\
23 \text { females and } 11 \text { males } \\
50 \% \text { presented with post } \\
\text { operative infection events on the } \\
\text { 3rd day. No significant difference } \\
\text { between the } 2 \text { groups. } \\
\text { No significant difference } \\
\text { observed in the level of oedema } \\
\text { between the } 2 \text { groups. } \\
\text { Increased mouth opening in the } \\
\text { intervention group compared } \\
\text { to the control only on day } 3 \\
\text { (P=0.29) } \\
2 \text { cases of dry socket ( } 1 \text { in the } \\
\text { intervention group presented } \\
\text { on day } 3 \text { and one in the control } \\
\text { group presented on day } 7 \text { ) } \\
3 \text { cases of purulent discharge } \\
\text { observed in the control group } \\
\text { only }\end{array}$ & $\begin{array}{l}\text { Small sample size } \\
\text { Wide gaps between re evaluation } \\
\text { dates } \\
\text { study only on health patients. } \\
\text { Excluded high risk patients } \\
\text { Post operative home care may have } \\
\text { influenced the outcome such as } \\
\text { the use of chlorhexidine gluconate } \\
\text { mouthwash. } \\
\text { The study used only a single type of } \\
\text { antibiotic and did not look into the } \\
\text { effects of other antimicrobial agents } \\
\text { on post operative infections }\end{array}$ \\
\hline $\begin{array}{l}\text { Halpern L, et al (2007) } \\
\text { Does Prophylactic Administration } \\
\text { of Systemic Antibiotics Prevent } \\
\text { Postoperative Inflammatory } \\
\text { Complications After Third Molar } \\
\text { Surgery? } \\
\text { Setting: Oral and Maxillofacial } \\
\text { Surgery Ambulatory Clinic at } \\
\text { Massachusetts General Hospital, USA }\end{array}$ & $\begin{array}{l}\text { Design: double-blind, placebo- } \\
\text { controlled, randomized clinical trial } \\
\text { (RCT) } \\
\text { Subjects: } 118 \text { healthy subjects who } \\
\text { requested wisdom tooth removal } \\
\text { under intravenous sedation or } \\
\text { general anaesthesia. Mean age of } \\
24.4 \text { years. } \\
\text { Intervention: } \\
\text { Subjects wererandomly assigned } \\
\text { to either the active treatment } \\
\text { (antibiotic) or placebo (0.9\% normal } \\
\text { saline) groups. The antibiotics } \\
\text { used were penicillin (15,000 units } \\
\text { per kilogram) or, for penicillin- } \\
\text { allergic subjects, clindamycin (600 } \\
\text { mg). The antibiotic or placebowas } \\
\text { administered intravenously one } \\
\text { hour prior to the surgical incision. } \\
\text { Control: } 0.9 \% \text { normal saline } \\
\text { Outcome: Post - operative infection } \\
\text { was determined by the presence of } \\
\text { alveolar osteitis (A0) or surgical site } \\
\text { infection (SSI). }\end{array}$ & $\begin{array}{l}\text { In the active treatment group, } \\
\text { there were no AO or SSIs. } \\
\text { In the placebo group } 5 \text { subjects } \\
(8.5 \%) \text { were diagnosed with } \\
\text { SSIs }(P=.03) \text { and no subjects were } \\
\text { diagnosed with AO. } \\
\text { The subjects who developed SSIs } \\
\text { had surgical removal of impacted } \\
\text { third molars with bone removal. }\end{array}$ & $\begin{array}{l}\text { All the subjects received intravenous } \\
\text { dexamethasone ( } 8 \mathrm{mg} \text { ) pre - } \\
\text { operatively. Since dexamethasone } \\
\text { reduces the amount of inflammation } \\
\text { this could have reduced the post - } \\
\text { operative complications. } \\
\text { The study only investigated the } \\
\text { effectiveness of intravenous } \\
\text { antibiotics and not systemic oral } \\
\text { antibiotics. } \\
\text { Smokers were not excluded from the } \\
\text { study which may have affected the } \\
\text { results since there is a link between } \\
\text { infections and dry sockets with } \\
\text { smoking. } \\
\text { Post operative home care may have } \\
\text { influenced the outcome such as } \\
\text { the use of chlorhexidine gluconate } \\
\text { mouthwash. } \\
\text { As this is a single centre and single } \\
\text { surgeon study, the results cannot be } \\
\text { generalised to a wider population. }\end{array}$ \\
\hline
\end{tabular}


patients who were at a risk of infection and poor wound healing such as diabetics. Those with existing dental abscesses or localised pathology such as a cyst near the tooth were also excluded. All the subjects were ASA grade I with a mean age of 25.4 years.

Subjects were assigned to the treatment group or placebo group randomly with an equal number of subjects in both groups $(n=59)$. Both the subject and surgeon were blind to the intervention. The subjects were administered with either intravenous antibiotics or $0.9 \%$ saline one hour prior to the surgical incision. The antibiotics used were either amoxicillin $(15,000$ units per kilogram) or clindamycin $(600 \mathrm{mg})$ if patients had a penicillin allergy. All subjects were followed up seven days after the operation. The outcome measured was either the presence of a surgical site infection (SSI) or alveolar osteitis (AO). The authors have outlined in the study how they diagnosed either a SSI or AO.

The results obtained showed that in the active treatment group, there were no AO or SSIs. However in the placebo group 5 subjects $(8.5 \%)$ were diagnosed with SSIs $(P=0.03)$ and no subjects were diagnosed with AO. The subjects who developed SSIs had surgical removal of impacted third molars with bone removal.

\section{Discussion}

Although in the Bezerra et al. [3] trial the patients had at least one indication for the removal of all 4 third molar teeth, the study excluded patients who are at high risk of developing post-operative infections. Patients on the contraceptive pill, those with existing periodontal disease, smokers and medically compromised patients were excluded. Patients with a history of antibiotic allergy were also excluded. It is important to note that high risk patients or patients with poor oral hygiene are more likely to present with post-operative infections and may therefore benefit more from prophylaxis than healthy patients. A total of 38 from an initial cohort of 800 subjects enrolled for the trial met the inclusion criteria for the study. Therefore this sample size was too small to reach a conclusive conclusion.

The re-evaluation date ranged from 3,7 to 14 days. This means that short term infectious episodes may have resolved and therefore were missed by the time the re-assessment was made. It is important to note that the procedures were conducted by an experienced oral surgeon and therefore it is likely to assume there was less surgical trauma associated with the extractions. Amoxicillin was the only antibiotic used in this study and no comparison to other antibiotics was made. Narrow spectrum antibiotics such as metronidazole, anaerobic antimicrobial and other antimicrobial agents were not investigated.

During the Halpern et al [4] study all subjects were given intravenous dexamethasone $(8 \mathrm{mg})$ pre - operatively. Since dexamethasone reduces the inflammation this may have had an influence on the amount of post-operative inflammation in the surgical site. Smokers were not excluded from the study and as there is a strong correlation between smoking and the incidence of dry sockets and infections, this may have influenced the results.
The authors do not state whether or not those 5 patients who developed SSIs were smokers. There is also no mention on the post-operative home regimen of the participants. For example, the patients may have used chlorhexidine gluconate mouthwash at home which may have reduced the prevalence of infection. The study is also specific to the surgical removal of third molars, and therefore we do not know if the same results may have been obtained if the authors studied the outcomes on the surgical removal of other teeth.

\section{Conclusion}

As no substantial evidence was established from this search, it is essential to weigh the benefits of antibiotic use against the possible risks when considering pre-operative prophylaxis. As demonstrated in the two appraised articles, in young healthy adults pre-operative antibiotics presented no additional benefits and therefore the use of antibiotics routinely prior to surgical removal of third molar teeth is not indicated.

Patients with grossly carious teeth, active periodontal disease and those groups at higher risk of developing infection may benefit from antibiotic prophylaxis but there is inadequate scientific evidence to determine this. However, most studies in the literature are on the surgical removal of third molars, which are more difficult to remove and are often associated with increased soft tissue trauma.

Although the clinical evidence is limited, pre operative intravenous antibiotics may help to reduce the incidence of post operative infections in patients undergoing surgical removal of teeth including third molars. However, the prescribing of antimicrobials includes risks such as anaphylaxis, development of resistant bacteria and unfavourable side effects such as gastrointestinal and neurological disturbances [5] and must therefore be prescribed only when necessary.

\section{References}

1. Lodi G, Figini L, Sardella A, Carrassi A, Del Fabbro M. et al. (2012) Antibiotic to prevent complications following tooth extractions . The Cochrane Database of Systematic Reviews 11: CD003811.

2. Daly B, Sharif MO, Newton T, Jones K, Worthington HV (2012) Local interventions for the management of alveolar osteitis (dry socket). Cochrane Database of Systematic Reviews 12: CD006968.

3. Bezerra TP, Studart-Soares EC, Scaparo HC, Pita-Neto IC, Batista SH, et al. (2011) Prophylaxis versus placebo treatment for infective and inflammatory complications of surgical third molar removal: a splitmouth, double blind, controlled clinical trial with amoxicillin (500mg). J Oral Maxillofac Surg 69(11): 333-9.

4. Halpern LR, Dodson TB (2007) Does prophylactic administration of systemic antibiotics prevent postoperative inflammatory complications after third molar surgery?. J Oral Maxillofac Surg. 65(2):177-85.

5. Poeschel PW, Eckel D, Poeschel E (2004) Postoperative prophylactic antibiotic treatment in third molar surgery-a necessity?. J Oral MaxillofacSurg 62(1): 3-8.

6. Sekhar CH, Narayanan V, Baig MF (2001) Role of antimicrobials in third molar surgery: prospective, double blind, randomized, placebocontrolled clinical study. Br J Oral Maxillofac Surg. 39(2):134-7. 
7. Lawler B, Sambrook PJ, Goss AN (2005) Antibiotic prophylaxis for dentoalveolar surgery: is it indicated? Aust Dent J. 50(4 Suppl 2):S549.

8. Schwartz A B, Larson E L (2007) Antibiotic prophylaxis and postoperative complications after tooth extraction and implant placement: a review of the literature. J Dent 35(12): 881-888.

9. Munckoff W (2005) Antibiotics for surgical prophylaxis. Aust Prescriber 28:38-40.

10. Piecuch J F, Arzadon J, Liebich S E (1995) Prophylactic antibiotics for third molar surgery: a supportive opinion. J Oral Maxillofac Surg 53(1):53-60.
11. Martin MV, Kanatas AN, Hardy P (2005) Antibiotic prophylaxis and third molar surgery. Br Dent J 198:327-330.

12. Curran JB, Kenneth S, Young AR (1974) An assessment of the use of prophylactic antibiotics in third molar surgery. Int J Oral Surg 3(1):16.

13. Harvey K, Rogers S, Roughead L (1999) Initiatives to improve antibiotic use. Aust Prescriber 22:26-28.

14.Zeitler D L (1995) Prophylactic antibiotics for third molar surgery: a dissenting opinion. J Oral Maxillofac Surg 53:61-64. 